\title{
Being a good relative: Indigenous doulas reclaiming cultural knowledge to improve health and birth outcomes in Manitoba, Canada
}

\author{
Jaime Cidro*, Caroline Doenmez, Ari Phanlouvong and Ali Fontaine \\ Department of Anthropology, The University of Winnipeg, Manitoba, Canada
}

\begin{abstract}
Indigenous women are increasingly returning to culturally based birthing practices to assert their sovereignty over their bodies and their birthing experience generally. The impact of colonization on birthing experiences for First Nations women in Canada has been profound and extends into generations of families. First Nations women across Canada have traditionally birthed in their communities surrounded by families and community, observing many traditions around pregnancy and birthing including placenta burying and belly button ceremonies. These traditions and this circle of care and support resulted in resiliency, strength and a connection to the land and family. In Manitoba, Indigenous women are becoming trained and engaged in supporting their fellow Indigenous relatives and community members as Indigenous doulas or birth workers. This paper describes the experiences of the first cohort of Indigenous doulas trained in Winnipeg, Manitoba by the Manitoba Indigenous Doula Initiative (MIDI), also known as Wiijii'idiwag Ikwewag, and describes the specific contributions and impacts of Indigenous doulas who support Indigenous women during pregnancy and birth. Through qualitative interviews, our participants described various understandings of their work, purpose and their impacts on the women and families they support. Four recurring themes which emerged across the interviews included: prior negative birthing experiences, clashes with mainstream health and social services, the understanding of doulas as advocates, and empowerment and disempowerment. These themes all spoke to ongoing challenges Indigenous women continue to face during their pregnancies and births in mainstream healthcare systems, as well as highlighting the key forms of support that doulas can provide to ensure the self-determination and well-being of the women they work with.
\end{abstract}

\section{Introduction}

Indigenous women are increasingly returning to culturally based birthing practices to assert their sovereignty over their bodies and their birthing experience generally. The impact of colonization on birthing experiences for First Nations women in Canada has been profound and extends into generations of families. First Nations women across Canada have traditionally birthed in their communities surrounded by families and community, observing many traditions around pregnancy and birthing including placenta burying and belly button ceremonies. These traditions and this circle of care and support resulted in resiliency, strength and a connection to the land and family. In Manitoba, Indigenous women are becoming trained and engaged in supporting their fellow Indigenous relatives and community members as Indigenous doulas or birth workers. This paper describes the experiences of the first cohort of Indigenous doulas trained in Winnipeg, Manitoba by the Manitoba Indigenous Doula Initiative (MIDI), also known as Wiijii'idiwag Ikwewag, and will describe the specific contributions and impacts of Indigenous doulas who support Indigenous women during pregnancy and birth. This paper will first provide background on some of the historical context of removing birthing from First Nations communities, the health implications of maternal evacuation, the role of support for expectant mothers, and Indigenous doulas as culturally based support. Following this, the paper will describe the research methodology that was employed, the results of our interviews and a discussion of the impact of Indigenous doulas, specifically for First Nations women who travel for birth.

\section{Historical context of birthing in First Nations communities}

Prior to the formation of Canada as a colonial nation, a traditional midwife attended births, or during periods of travel birthing women were aided by a spouse or family member [1]. The knowledge around birthing infants was transmitted inter-generationally and included not only physical logistics of birthing, but also traditional medicines to deal with a range of issues associated with delivery and postpartum [1]. First Nations women, especially those in remote communities, continued to receive maternity care from traditional midwives in the community. Due to interruptions from imposition of colonial policies and practices, this care transferred from home births to births in nursing stations with Federal nurses who had midwifery training [2]. Furthermore, this transfer of responsibility from traditional roles within the community to external service providers diminished and eventually led to the role of traditional midwives and doulas becoming diminished. Across Canada, the colonization of birthing was well underway and as Jasen [3] describes the government began to focus on reducing infant mortality as a part of these changes. As the overall health of First Nations people declined, "an assimilationist policy was directed towards bringing childbirth among these women under direct

${ }^{\star}$ Correspondence to: Jaime Cidro, Department of Anthropology, The University of Winnipeg, 3RC086, 599 Portage Avenue, Winnipeg, Manitoba, Canada, Tel: 204-789-1417; E-mail: j.cidro@uwinnipeg.ca

Received: October 08, 2018; Accepted: October 26, 2018; Published: October 31,2018 
government control. Subjected, simultaneously to ideologies of both gender and race, Aboriginal people underwent a particularly stark transformation in their reproductive lives [3].

By the 1970s, the efforts to decrease maternal mortality and morbidity in the general population led to a move towards hospital deliveries for all women. For First Nations women in particular, this led to their being transferred out of their home community weeks before their due date, an event which often resulted in poor social consequences $[4,5]$. The evacuation policy is still in effect today, with women leaving their communities at 36-38 weeks gestation [6] and "confined" to a boarding home or motel in a tertiary care centre to wait for labour to commence. In addition to the negative social outcomes to families and women who birth outside of their community, the infant mortality rate among First Nations remains twice as high as the Canadian average [7]. In Manitoba it was found from 1991 to 2000 that the infant mortality rate for First Nations (Status Indians on reserve) and off-reserve was 10.2 deaths per 1,000 live births, or 1.9 the 'nonFirst Nations' IMR of 5.4 per 1,000 [8].

As Varcoe et al. [9] stated, the role and dominance of biomedicine has resulted in the imposition of medically based maternity technologies and Indigenous women are now in a situation where they are being told that "their time honored midwifery and birthing practices were unsafe and that they must turn to the advances of western medical practice for "modern" maternity care" (p. 7). The impact of this message, and how it is operationalized are significant to the physical and mental health of First Nations women and families.

\section{Indigenous women's political bodies}

The historical context of birthing, and the slow removal of local midwifery care from Indigenous communities to tertiary care centres is intimately connected to the larger politicization of Indigenous women's bodies and their reproductive health. The dominance of biomedicine for Indigenous women also cannot be separated from the politicization of Indigenous bodies in a colonial context $[10,11]$. Simpson [10] describes how the settler state has a "death drive to eliminate, to contain, to hide and in other ways disappear what fundamentally challenges its legitimacy: Indigenous political orders" and that Indigenous women represent these alternative political orders and thus are targets for destruction. Kahnawake Mohawk scholar Audra Simpson [10] also asserts that Indigenous women were in fact a threat to the colonial project and that the destruction of their bodies, whether physically or metaphorically is really about diminishing political systems often led by women, to ones that were more politically aligned with colonial ways of ruling. Building on these ideas, Michi Saagiig Nishnaabeg scholar Leanne Betasamosake Simpson [11] describes the impact of colonization on her maternal side and looks directly at Canada's Indian Act and notes: "A large part of the colonial project has been to control the political power of Indigenous women and queer people through the control of our sexual agency because this agency is a threat to heteropatriarchy...Indigenous body sovereignty and sexuality sovereignty threaten colonial power (p. 96)." Similarly, Anderson [12] draws our attention to Indigenous motherhood and family as a key target of colonialism; she writes: "Empowered motherhood was not only a practice but also an ideology that allowed women to assert their authority at various political levels" (p. 83-84). These authors all clearly make the link between the way Indigenous women's bodily and political power have been undermined throughout generations of colonial interference [10-12]. We draw on this work as we consider the role of culturally based doulas because of the focus on re-centering Indigenous women's own knowledge and boundary-making during the birth process which is in direct opposition to the colonial approach to reproductive health that currently dominates health care.

\section{Health impacts of travel for birth}

Forced evacuation for birth is associated with colonial practice and is seen as a cultural loss [13]. Women are now faced with having to choose culture over risk, resulting in "diminishing birthing choices, with loss of connection to family, clan and culture when they left their communities to give birth" [9]. First Nations women who travel for birth experience a range of negative stressors such as "loneliness, disconnection from community, isolation from family and culture, and discrimination" in addition added stress and anxiety related to the management of family life while they are away, that exacerbate existing poor pregnancy and infant health conditions [9]. Chamberlain and Barclay [5] describe three main psychological impacts of travelling for birth for Inuit women as emotional, physical and economic stressors. Emotional stress referred to "enforced separation from family, culture and the community as a result of being sent out for birth" (p. 118). Physical stress included lack of help with breastfeeding resulting in pain, and a rapid birth with no pain inhibitors. Economic stress included family costs such as phone calls, babysitters, and airfare for partners [5]. Economic stress is also described by Varcoe et al. [9] where "a woman with limited resources associated their postpartum depression primarily with a lack of family and community support before, during and after birth" (p. 4). Having a stressful birth contributes to postpartum depression and affects the capacity to bond with and nurture infants [9].

Healthy pregnancy and infancy indicators (teen pregnancy, preterm birth, low and high birth weight, infant and neonatal mortality) are well documented to be two to five times worse for Aboriginal people in Canada, with low birth weight and preterm birth weights getting worse [9]. Women who are able to give birth with support from families during delivery "connected those experiences to better outcomes" [9].

\section{Support}

One important factor for a positive birth experience for women is support. Continuous support is associated with shorter labours, a decreased need for the use of analgesics, oxytocin, forceps, Caesarean sections and higher levels of satisfaction with the birth experience. Continuous support has the greatest benefits when the support begins early in labour and when the provider is not an employee [14]. Psychosocial stressors and poor health outcomes associated with negative birthing experiences are important challenges facing primary care providers. However, to work successfully in First Nation communities, health care providers must be culturally competent, be able to apply their knowledge, have self-awareness, and have personal attributes and attitudes that facilitate respectful partnerships with communities [15].

The National Aboriginal Health Organization found that continuous emotional and social support to women during childbirth has positive impacts, not only for labour and delivery, but also on breastfeeding rates and attachment [16]. The basis for support for First Nations women who birth is a positive relationship. According to research with First Nations communities in $\mathrm{BC}$, the positive and stressful aspects of relationships with care providers were underpinned by "respect, understanding of cultural context and connection with communities" [9]. In the case of birth experiences of Inuit women, the Inuit maternity worker provided additional psychosocial support in the birthing centre and "she spent a great deal of time on personnel 
counselling with abused women even though this had not initially been seen as part of her role" [5].

\section{Culturally based support through doulas}

Doula is a Greek term that has its roots in the tradition of women supporting other women during pregnancy, labour, birth and postpartum. Doulas are not a new caregiving role, and in fact this role was provided by family members or a local woman who was experienced [17]. The more formalized doula care provider as we know it today is the result of women living away from their families, and in the case of First Nations women, being forced to birth away from their home community away from family members. The need for more support for women emerged as a formal birth companion role. A doula provides continuous physical, emotional, and advocacy support during labour and birth, but does not provide medical or midwifery and nursing care [17].

For First Nations women, the move from births in home communities to births in tertiary care centres has meant the loss of traditional teachings, elders and a birthing mentor. The role of an older female relative is documented as an important component of pregnancy and childbirth, and critical cultural practices that are respected as essential to establishing and revitalizing the strong cultural connection and spiritual path for First Nations children. As Wiebe et al. [15] describes, "the attention from older people in the community enhanced the mother's self-confidence and sense of empowerment, because these relationships constituted a powerful and enduring connection which extended to her unborn child" (p. 54). In research conducted in an Alberta First Nation, the role of doulas was identified as a central recommendation to addressing childbirth and infant health. They noted that First Nations women should be trained and accompany the pregnant women through the entire process, and provide prenatal teaching, connections, support, and a liaison role with health care professionals in the mainstream system as needed [15]. They also noted that the strength and knowledge already exist in the community and that they "just need the confidence and certification to get into the classroom. Often the elders are tired, but maybe the younger grandmothers could accompany the pregnant women" [15]. Culturally based doulas are not solely about providing improved birth experiences for women and families, but also about rejecting the dominant, often medicalized reproductive health practices. These doulas provide a pathway back to retrieving women centered knowledge around women's bodies, infant care and parenting that promote resiliency in Indigenous families.

\section{Methodology}

In 2016 to 2017, Indigenous women in Manitoba were a part of the first Winnipeg cohort of Indigenous doulas trained through the MIDI. In a pilot project in partnership with the Winnipeg Boldness Project, the First Nations Health and Social Secretariat of Manitoba, and Mount Carmel Clinic, twelve women were trained and provided doula care for Indigenous women in Winnipeg and Northern Manitoba. In preparation for a larger project that focused on training Indigenous women in northern remote First Nations communities where expectant mothers travel for birth, we interviewed this cohort to assist the research team in identifying how to address the needs of both the doulas and Indigenous families receiving doula care. We invited the doulas to participate in interviews in the summer of 2017. Nine out of twelve doulas were interviewed using the "conversational method" [18] where we discussed their experiences as Indigenous doulas, their motivation for doing this work, and what they would advise for new doulas being trained that focused on First Nations women who travel for birth. The MIDI and the Winnipeg Boldness Project reviewed the interview questions. The research underwent research ethics review from the University of Minnesota and was determined to be exempt due to lack of collection of private identifiable information about the participants themselves personally. The project also received approval from the University of Winnipeg research ethics board. The interviews were conducted in a local Indigenous café in the neighbourhood where the Indigenous doulas lived and lasted about one hour each. Interviews were always recorded by at least two of the interviewers to ensure that if one recording was flawed or damaged an alternative copy was available. Once all interviews had been completed, the researchers divided them up and each transcribed several of them verbatim. The full transcripts were then sent to the doulas for approval. They were given several weeks to send feedback to the research team with any edits they wanted made to their transcripts. Once transcripts had been approved by the doulas, the researchers proceeded to develop a coding framework as a group using the constant and comparative method and drawing from grounded theory $[19,20]$ to identify recurring themes. A line-by-line analysis was then conducted of each transcript by each researcher. The results were then compiled and categorized into major themes/ categories. The initial coding framework focussed on actions rather than themes to avoid making any conceptual leaps and adopting extant theories prior to the analysis [21]. Following this, the research team tested the initial coding framework independently by reviewing a set of transcripts. The coding framework was adjusted after team discussion and the transcripts were subsequently coded using a selective approach to identify the themes most pertinent to the original objectives of the [22]. The research team engaged in constant comparison between the categories as well as with the other authors, which entailed "sensitivity to differences between emerging concepts/categories" [23]. Agreement was reached at all points where inconsistencies were noted and then all interviews were coded to ascertain which themes reoccurred most frequently.

\section{Results}

In the interviews, multiple topics were addressed as significant dimensions of the doulas' understanding of their work, purpose and their impacts on the women and families they support. Four recurring themes which emerged across the interviews included: prior negative birthing experiences, clashes with mainstream health and social services, the understanding of doulas as advocates, and empowerment and disempowerment. These themes all spoke to ongoing challenges Indigenous women continue to face during their pregnancies and births in mainstream healthcare systems, as well as highlighting the key forms of support that doulas can provide to ensure the self-determination and well-being of the women they work with.

\section{Prior negative birthing experiences}

One of the most consistent themes throughout the interviews was that of the Indigenous doulas having personally experienced or witnessed what were described as negative births. Several of the doulas reflected on patterns of stressful, frustrating, or frightening birthing experiences that had impacted them, their mothers, grandmothers, sisters, friends and clients. Some of them described feeling alone, overwhelmed, and terrified while in hospitals. Moreover, in their descriptions of giving birth to their own children it emerges that many of them felt that their autonomy was taken away. Their own input, ideas or questions were muted. For example, one doula noted that during the birth of her first child, she felt largely uninformed about the process 
and unable to voice her thoughts to her doctors, resulting in a sense of fear and subordination:

So, for my first one, I wasn't sure what was going on, I didn't know what to expect, and it was really kind of a scary experience for me going through that and sort of doing what the doctor tells you what to do, not knowing that I could ask questions and maybe decline some things or be more involved in some of the decisions. I was really kind of unhappy after...

Another doula similarly described feeling as though she had to simply be a passive recipient of the doctor's care, without any sense of being able to shape her experience: "My own delivery was pretty clinical. And I didn't know what choices I had; it just seemed up to them." Moreover, these patterns were not necessarily understood to be aberrant or new; some of the doulas had stories about women of earlier generations in their families being subjected to similarly disrespectful treatment. For example, this same doula revealed that her own mother had been subjected to a nonconsensual procedure during her birth:

...it was even worse with my mom, in the 60s. Because when I was born, the doctor put my mom under. I'm the third child. So, my mom had had two healthy pregnancies, healthy deliveries prior to me. But the doctor put her out with gas and then delivered me with forceps. And there was no reason, and my mom didn't consent to it, she was like, 'What's going on?' and by this time she's already going unconscious.

This kind of nonconsensual or coercive behavior on the part of the medical professionals remains an ongoing area of concern for many of the doulas. One of them told a story about a woman she had recently been assisting during a long birth. When she left the room briefly, a doctor intervened and popped the woman's water while she was sleeping: "And so then she was terrified cause she was like....'I don't know if I can talk to them or not,' and it didn't matter, she just felt at that point that they weren't going to listen to her anyways."

\section{Clash with mainstream health and social services}

As the previous section indicated, many of the doulas expressed feelings of dissatisfaction towards the existing healthcare system when it comes to Indigenous women's experiences of prenatal care, delivery, and postpartum care. There was a widespread consensus regarding the typical power dynamic between the women and the "expert" medical professionals, who often didn't respect or make room for their voices in the process. This kind of treatment can be intrusive or incompatible with Indigenous understandings of wellbeing. One doula pointed out that there are few Indigenous people in certain healthcare settings; at one that she had worked at, she was one of two Indigenous women working in the entire institution. Additionally, these medical professionals often are not prepared to incorporate traditional Indigenous knowledges or practices into a delivery. One doula described how she had talked to a non-Indigenous midwife about wanting to keep the placenta, only to have her make a joke about it, which led to her abandoning the idea: "I just sort of felt kind of discouraged and so I didn't bring it up again."

\section{Child apprehension}

In addition to these concerns, the issue of babies being apprehended was one of the most searing themes that reoccurred in nearly every interview we conducted. In fact, one of the main roles the doulas articulated as part of their work was to support mothers and babies targeted by the system. This responds to the overwhelming overrepresentation of Indigenous children in the welfare system in Manitoba, where they make up almost $90 \%$ of children in CFS care,
[24] prompting Indigenous Services Minister Jane Philpott to declare the situation a "humanitarian crisis" in 2017 [25]. One doula articulated the need for doulas to work against these removals:

And our most vulnerable population, our newborn babies, are at risk too. It's my hope that somehow the doulas can become involved with the First Nations Family Advocate Office to be able to provide support and to be able to be a resource so that it encourages more babies to go home with their families, knowing they have a support circle. They have a resource person, they have this team that they can draw on if they need help with anything on any level, who will come right away...And we have set out a call to action, that this needs to stop, the apprehension of our children needs to stop...And our babies need to be safer, our babies need to be cared for.

The possibility of Indigenous women's babies being taken away from them can be a source of great trauma in the delivery room, where social workers have been known to appear without any prior warning and sometimes leave with the infant. One doula, who herself had been in foster care as a child, reported how a social worker appeared unannounced at her bedside after the delivery of her son:

And she came after all of my supports left, after my family left, she thought my husband wasn't even in the room, and she came and she tried to talk to me when I was by myself, and really vulnerable....And that was one of my biggest fears, because my mother- my biological mother-both my brother and I, we were apprehended into care by child protective services. And so, it was just like, I thought that her history would influence my future. Right? And so when she came, it was really scary. It was on the last day before we were going to be released, and it was just like, 'Man, we might not get out of this hospital.'

The sense that CFS workers could intrude into the hospital and potentially take their children away contributes to the perception of hospitals as unsafe spaces. The doulas articulated the extent to which the threat of child removal impacts many Indigenous women's experiences of pregnancy, birth and motherhood. Even when these mothers, like this interlocutor, end up keeping their children, the stress and anxiety of knowing they could or might be visited by social workers in the hospital often transforms their experience of birth into one of fear. Thus, many of the doulas were adamant about creating spaces that feel safe for Indigenous women to give birth and considered an integral part of their role to be defending these mothers and babies from CFS workers. Critically, however, the doulas clarified that even when their work cannot prevent an apprehension, they still see a vital role for themselves in standing with the mothers:

"This is what's happening to me," and then having someone hear that, validate your need for help, and then come cover and protect you. And even if that means that we don't prevent the intervention, just to see a show of support and community and know that they believe you. And know that you're not bad, and you're not wrong, and you're not any less of a mother or human being because of what happened. And just like, that is healing.

In this sense, birth work represents a much larger project than simply facilitating a healthy physical birth. Rather, it is the establishing and maintaining of a set of relationships that sustain and support the mothers no matter what they go through.

\section{Advocacy}

As the previous section suggests, one of the primary roles that doulas identified in their work was serving as advocates for the women 
they are working with, or as mediators between the women and their doctors or nurses. One of them described being asked by a family to attend a meeting between one of her clients and CFS, where she helped the dialogue between the two groups and advocated for the mother. In another situation, her advocacy was rooted in being able translate for a mother with language barriers: “Another mom didn't speak the greatest English and she didn't understand why she wasn't able to leave the hospital, but it was because her baby was having withdrawals. So I was talking between...the nurses and them." A different doula reiterated the significance of simply being able to translate dense or obscure medical jargon used by the doctors and nurses into comprehensible language for her clients: "Just me being there, being able to bridge that gap, it brought the tension way down because they never seem to explain things." Another doula noted how her presence seemed to get the attention of the doctors when they were being inattentive to one of her patients:

I know one of my moms in particular, when she was in the hospital, at first she was there for a while - she was being induced because she had gestational diabetes - and I think having someone because her partner, he was at home with their other kids, and she was sort of being a little neglected by the system, so when I was there, they sort of did more when they saw that there was someone else there helping her. So, I think that that makes a big difference, too. If they don't have a support person, when we're there, all of a sudden, I think they take notice of that woman more, it seems.

Several doulas also noted that while there may be questions that they don't know the answer to, they can help connect their clients with relevant resources, or simply walk them through the process of finding out the answer together. Providing this kind of consistent, patient and flexible support to the mothers and their families is one of their primary responsibilities; giving them a sense of their options, helping them access knowledge, navigating the systems with them, and serving as a companion, so that the women can shape their own experience as much as possible.

\section{Empowerment and disempowerment}

Given the key element of the doulas' work is to re-center Indigenous women's autonomy, knowledge and boundary making during the birth process. One way of characterizing this is body sovereignty: “...it's like consent...Knowing that your body is one hundred percent yours... If you don't feel comfortable in a certain environment, you can go." Another doula stated that for her, body sovereignty meant encouraging Indigenous women to voice their limits and needs throughout the process:

And you know, the right to say, 'No,' on all levels: emotionally, physically, mentally, spiritually, they have control over what happens and if they don't want me to touch them physically, if they don't want me to talk, I have to be mindful of that... But to know that it's okay, nobody's going to be mad at them.

This includes the women's abilities to refuse culturally relevant care if they do not feel comfortable receiving it. Several doulas attested to experiences with women who decided not to keep the placenta, offer tobacco, or participate in other aspects of cultural care that the doulas offer. The doulas stressed that their role is to support the woman no matter what she determines she needs.

For one doula, empowerment and body sovereignty was a way of conceptualizing connection and responsibility to previous and future generations. She explained how she theorizes the Seven Generations teaching alongside women's life-giving abilities:
It's not just about you choosing what's best for you, because of our teachings as Indigenous people. Technically we were in our grandmothers, we were physically inside of our grandmothers because a woman is born with every egg she's ever going to have... If you think about that, your grandma was inside of her grandma. Right? So, you can see where those seven generations come. So, body sovereignty isn't just about you in the here and now... you have a really great responsibility not only this way, but this way... That's why Indigenous women are so powerful.

This signals that for some Indigenous women, body sovereignty is not limited to the experience of their individual body but involves a consideration of and engagement with one's ancestors and future children. Another doula described the multi-temporal effects of assisting at the birth of her grandchildren, similarly attesting to the way that a sense of empowerment ripples across generations:

You go through another level of love. And not only love for that little human being, and the one who gave birth to it, but love for yourself, love for my mother. All these levels of these women in my family who have created life. The more that I strengthen and am empowered, the more that I reclaim my womanhood-ness, my grand motherliness, my femininity, sovereignty over my body, and reclaiming birth and taking that leadership role in my life, the more that the women that came before me and the women who come after me can do the same on deeper levels. I'm healing what happened and building a future.

\section{Doulas' empowerment through the training}

In addition to noting how much of an impact Indigenous birth work can have on pregnant women, the interviews suggested that one of the key elements of this kind of project is the extent to which the birth workers themselves can be transformed or nourished through this training and practice. In their interviews, many doulas emphasized how powerful this training process had been. One them stated:

...it was one of the most empowering times for me as a woman. And everybody took the lead at one point, some of our morning or our water ceremonies; everyone jumped in and shared their gifts. And the kindness...And talking about the ceremonies at birth, and the teachings about where life comes from, where they travel through the star world and come into the body: all of that was so incredible. And it helped a lot of the things I'd heard from the elders click together...the seven days we spent together-were sacred. It was like ceremony for me.

Another doula described how for most of the members of the first cohort, the training was an emotional experience which brought up difficult memories but also gave them the space, time and tools to work through them.

I think it's been empowering for the women that we've been working with, but I think it's been empowering for us as the doulas also... We're all on our own healing journeys too...I think learning about our bodies and learning about taking back birthing and making it more of a sacred, spiritual journey, I think has been really kind of healing and empowering for us who have been in the program. I think for me personally, because of some of the stuff that I had happen during my pregnancies and births too, it sort of made me reopen some of that but then help me deal with some of that.

\section{Knowledge}

Many of the doulas described how engaging with cultural knowledge around birth was empowering. They stressed that providing culturally relevant care consists of understanding and working with each woman's family or community traditions. For many women, 
simply having a doula ask about their family's birth traditions was the catalyst for them to turn to family or community members to learn about these practices and stories. Most of the doulas agreed that traditional knowledge around birth is not widely known. Thus, the training becomes an experience through which some women reconnect to epistemologies and modes of care, which had been destroyed or suppressed throughout colonization. One doula explained: "It's not a matter of convincing one person one story. It's about teaching people to go back and look at their own stories, their own families, their own teachings or their backgrounds and where they come from. I think that was probably the biggest thing that we learned because we could go to our moms and say, 'What are your teachings? What did your family do?' A lot of the times they didn't know it, but they would go ask and they would find out." One doula contextualized the importance of recuperating traditions and knowledge by noting how much of it remains obscured even today:

And so then to have been able to have the drum, sing a baby into the world, just like how much that kind of changes everything, you know? And it kind of invites that spirit or that presence to kind of protect, comfort mom and baby and family that are part of it. And I just think that not having it is why we need it. You know? Because it just shows how much-even in the years of reconciliation or whatever now-how much is unknown. And how much that knowledge is not necessarily accessible to everyone.

In this sense, the doulas are able to serve as teachers and facilitators, helping women and their families to discover or restore these teachings. This takes on a specific resonance for those who were raised away from their families. For example, one doula who had been raised in foster care described how the training became a space for her to begin engaging with some of the knowledges that had been denied to her growing up. Moreover, she noted that, as someone not raised with these traditions, she has sometimes faced skepticism and criticism from other Indigenous people who have questioned her authenticity. For her, the doula training not only gave her access to some of the lessons she'd been seeking, but also legitimated her journey in this direction. She said:

And what was so awesome about the training was that, being raised in care; I didn't have access to my culture, or traditions and teachings. And it's kind of a scary journey, as an adult, being on the outside and trying to come back into the fold. Sometimes- some of the conflicts I come into is the "You're not Native enough..." And that's really hurtful, and can be really harmful...So then, inside of the training, it was all rooted in Indigenous culture and practice, and then we got to learn so many different things that-now that I know, no one could ever take away from me. And so it's just like- that gave me a real sense of empowerment, and a real grounding and rooting in my culture and teachings. And also really affirmed the way that I'd been moving intuitively towards my culture and traditions.

For some doulas, the training in Indigenous philosophies, ceremonies and practices of care around pregnancy and birth allowed them to fulfill roles in their own lives that they had previously been unable to perform. One doula described what it was like to realize she could become the very person whom she had needed when her first granddaughter had been born. No one had been there to sing for her. When her second granddaughter was born last winter, she suddenly realized she was able to fulfill that past and present need: "And when she was born, I wanted to do something, I was: 'Someone should sing for her, someone should be saying something, someone, someone, someone.' And through the doula training, when the younger one was born in January, that someone was me."
Another doula described the importance of cultural teachings around birth as part of a lifelong project of being in the world:

The moment that that baby's born they're already surrounded in the world around them. So, if we're carrying them and walking in a certain way and thinking those good thoughts...then it's going to change everything. The effects of not having that is just being lost. Losing connections to our lands, we're not relatives anymore and it really shows because we don't walk those teachings. Those ones that were passed down to us and that would teach us how to, you know, live in peace and in a good way.

\section{Discussion}

While the women who participated in this project were primarily providing doula care to urban Indigenous women (except for two expectant mothers from Northern Manitoba), the Indigenous women still faced similar psychosocial consequences described by Varcoe et al. [9] and Chamberlain and Barclay [5] which were positively mitigated by culturally based birth support. In particular, these stories highlight the ways in which medical care providers can often undermine or violate Indigenous women's body sovereignty and self-determination, by taking steps without their full knowledge, consent or input. As Varcoe et al. [9] describes, where care providers can provide respectful, culturally aware care in which they are connecting to the Indigenous community of the birthing mother, then the stressful aspects of birthing can be mitigated. The doulas we interviewed described the role of Indigenous bodies as sites of management and even invasions as described by both Simpson [10] and Simpson [11], which can render their births as negative experiences. The work of the MIDI to reimagine and resituate birthing as something that should be celebrated rather than "endured" is central to this work. The doulas' statements revealed that many of them had first-hand, experiential knowledge of the challenges their clients may face while navigating the healthcare system, which helped them in their role as helpers of "good relatives".

In this sense, the doulas' testimony attests to the impact of having access to cultural knowledge and practices, both in terms of shaping an individual woman's experience of birth but moreover in articulating and practicing a connection to modes of care and worldviews which can inform all of life. While these may take different forms in each birth, and while many Indigenous women may not choose to base her experience in traditional knowledge, these stories signal the transformative and healing potential of having the option to do so. One doula described the overwhelmingly positive community response to MIDI as people being "hungry" for this kind of knowledge. This hunger is also connected to the values of bringing in older women or relatives described by Wiebe [15] to foster these enduring connections and relationships that fostered empowerment and self-confidence. We see this emphasis on empowerment and self-confidence as directly related to the experiences of Indigenous women who are vulnerable to the apprehension of their children from Child and Family Services.

These excerpts suggest that the doula training itself can be understood as a model for meaningfully engaging pregnant women as well as future birth workers through celebrating, training and validating their own experiences and expertise over their bodies. The role of Indigenous doulas as transforming how Indigenous women understand the power of their own bodies, their connection to culture and kinship networks, and the political space they occupy cannot be understated. 


\section{Limitations}

One of the limitations of this study was that the doulas had only been practicing for approximately six months when these interviews were conducted. Therefore, the information they were able to provide was based on experiences taking place within a relatively short period of time. Another limitation consisted of the fact that the research team was only able to meet with each doula once for a formal interview, as opposed to multiple times. Multiple interviews may have provided doulas more familiarity with the research team and given them time to reflect on some of the specific questions in a more sustained manner.

\section{Conclusion}

Doulas are birth helpers who provide emotional and spiritual support, as well as acting as advocates for the mothers in hospitals and birth centers. While the participants all noted that the term "doula" is unfamiliar to many in their communities, the concept of "birth helper" or even "sister" was one that resonated with them and the women they work with. Prior to the medicalization of birth, the delivery of a baby was a community event which provided relatives and friends the ability to support and celebrate pregnant women and the newborns entering into their midst. Whether referred to as "doulas," "birth workers," or "helpers" in their practices, Indigenous doulas are assuming this once-common role of women supporting women, providing culturally appropriate and community-driven care.

The doulas work to protect and advocate for Indigenous women in medical settings, which are often pronounced spaces of vulnerability for them. While not medically trained, they fulfill a wide array of their clients' needs: helping them fill out paperwork, answering questions, acting as a mediator between them and their doctor, helping them to sew moccasins or moss bags for the birth of their baby, singing with them, attending check-ups with them, preparing traditional teas, helping them create a birth-plan, and ultimately attending the birth to offer emotional and spiritual support. As one doula explained: "It's just being a sister. It's being kind. It's caring for someone else. Especially in that very vulnerable, intimate moment. So I think when we look at doulas, we see very mainstream stuff. But what we're actually doing is just being a really good relative; and I wish that people would change that word 'doula' out for 'being a relative.' Cause that's what it is." This observation is also tied to the fact that many of the doulas reported having previously served in roles supporting their community, whether it was conducting ceremonies, working with families, supporting youth who have witnessed violence, or assisting women in the corrections system.

It is key that the verb utilized by most of the doulas to describe the work they are doing was "reclaiming." This emits a sense of possibilityof restoring, of taking back pre-existing knowledges, practices and roles which were suppressed or dismissed, but that can be re-animated through programs such as the MIDI. Moreover, this birth work reestablishes their sovereignty over their bodies in a context where they are often violently denied that possibility. One of the doulas articulated her work as part of a bigger project to bring birth back to women and their communities:

I think birthing was taken away from our communities from our families and medicalized and turned over to often male doctors. It's something that we've always done with our women and didn't leave home, didn't have people - it just makes more sense to have your sisters, your mom, your grandmother, and the women in the community there for you to support you. I think birth justice, or reclaiming birth is another thing we've talked about just sort of bringing it back to the communities and bringing it back to the families.

The women who were interviewed for this project drew on their existing and enhanced understanding of the role of women as carriers of reproductive knowledge, and that central to this work is relationships or "just being a good relative". This preliminary project helped the research team carve out a clearer understanding of the role of both the urban doula and the doulas in the remote and northern First Nations communities. Specifically, it helped us understand that underlying this work is that treating Indigenous women with respect, choice and culturally based options will allow the woman to have more self-determination over her body and birthing experience.

\section{Ethics statement}

All of the doulas were informed prior to the beginning of the interviews what the study was about; what they would be asked to do; and that their participation was entirely voluntary and that they were under no obligation to take part in the study if they did not want to. Participants were also given the contact information of Dr. Jaime Cidro and Caroline Doenmez in case they had any questions. Each participant was compensated for their time with a $\$ 50$ gift certificate to Neechi Commons. This was provided in an effort to recognize the valuable time they were giving to us out of their busy schedules, as well as to acknowledge the labor of their conversations with us.

\section{Authorship and contributions}

Caroline Doenmez drafted the initial set of interview questions, which were then edited by the group. Caroline Doenmez, Ari Phanlouvong, and Alexandra Fontaine all conducted interviews together throughout July 2017, as well as transcribing and coding the interviews. Caroline managed communication with the doulas for arranging meetings, as well writing the initial draft of the paper with Dr. Jaime Cidro and with input from Ari Phanlouvong.

Dr. Jaime Cidro conceptualized and organized the project, sought and received the funding for it, facilitated the researchers' connections to research partners, oversaw the interviewing, transcribing and coding process, and helped finalize and submit the final manuscript.

\section{Acknowledgments}

We would like to acknowledge the support of our research collaborators, the Manitoba Indigenous Doulas Initiative (MIDI), the Winnipeg Boldness Project (WBP) and the First Nations Health and Social Secretariat of Manitoba. We also gratefully acknowledge the University of Winnipeg's Indigenous Scholars Program for the support of Ali Fontaine and the Master of Development Practice Program for the support of Ari Phanlouvong.

\section{Funding}

This project was funded by the Canadian Institutes of Health Research through the Institute of Aboriginal People's Health (IAPH).

\section{References}

1. Lalonde AB, Butt C, Bucio A (2009) Maternal health in Canadian Aboriginal communities: challenges and opportunities. J Obstet Gynaecol Can 31: 956-962. [Crossref]

2. Plummer K (2000) From nursing outposts to contemporary midwifery in $20^{\text {th }}$ century Canada. J Midwifery Womens Health 45: 169-175. [Crossref]

3. Jasen P (1997) Race, culture, and the colonization of childbirth in northern Canada. Soc Hist Med 10: 383-400. [Crossref] 
4. Society of Obstetricians and Gynecologists of Canada (2010) SOGC policy statement No. 251, December 2010. Returning Birthing to Aboriginal, rural, and remote communities. J Obstet Gynaecol Can 32: 1186-1188. [Crossref]

5. Chamberlain M, Barclay K (2000) Psychosocial costs of transferring indigenous women from their community for birth. Midwifery 16: 116-122. [Crossref]

6. Health Canada (2005) Clinical Practice Guidelines for nurses in primary care. Chapter 12: Obstetrics. Available from: http:/hc-sc.gc.ca/fniah-spnia/services/nurseinfirm/ clini/adult/index-eng.php.

7. McShane K, Smylie J, Adomako P (2009) Health of First Nations, Inuit, and Métis children in Canada. Indigenous children's health report: Health assessment in action p: 11-66.

8. Smylie J, Fell D, Ohlsson A, Joint Working Group on First Nations, Indian, Inuit, and Métis Infant Mortality of the Canadian Perinatal Surveillance System (2010) A review of Aboriginal infant mortality rates in Canada: striking and persistent Aboriginal/nonAboriginal inequities. Can J Public Health 101: 143-148. [Crossref]

9. Varcoe C, Brown H, Calam B, Harvey T, Tallio M (2013) Help bring back the celebration of life: a community-based participatory study of rural Aboriginal women's maternity experiences and outcomes. BMC Pregnancy Childbirth13: 26. [Crossref]

10. Simpson A (2014) The Chief's Two Bodies: Theresa Spence and the Gender of Settler Sovereignty. Unsettling Conversations, Unmaking Racisms and Colonialisms: $14^{\text {th }}$ Annual Critical Race and Anticolonial Studies Conference, University of Alberta, 1719 October 2014. https://vimeo.com/110948627

11. Simpson LB (2017) As we have always done: Indigenous freedom through radical resistance. University of Minnesota Press.

12. Anderson K (2010) Affirmations of an Indigenous feminist. Indigenous women and feminism: Politics, activism, culture, p: 81-91.

13. O'Driscoll T, Kelly L, Payne L, St Pierre-Hansen N, Cromarty H, et al. (2011) Delivering away from home: the perinatal experiences of First Nations women in northwestern Ontario. Can J Rural Med 16: 126-130. [Crossref]
14. Hodnett ED, Gates S, Hofmeyr GJ, Sakala C (2007) Continuous support for women during childbirth. Cochrane Database Syst Rev 16: CD003766. [Crossref]

15. Wiebe AD, Barton S, Auger L, Pijl-Zieber E, Foster-Boucher C (2015) Restoring the blessings of the morning star: childbirth and maternal-infant health for First Nations near Edmonton, Alberta. Aboriginal policy studies.

16. National Aboriginal Health Organization (2008) Exploring the role of social support in labour and delivery for first nations women and families, Ottawa.

17. Campbell-Voytal K, McComish JF, Visger JM, Rowland CA, Kelleher J (2011) Postpartum doulas: Motivations and perceptions of practice. Midwifery 27: e214-e221. [Crossref]

18. Kovach M (2010) Indigenous methodologies: Characteristics, conversations, and contexts. University of Toronto Press.

19. Lincoln YS, Guba EG (1985) Naturalistic inquiry (Vol. 75). Sage.

20. Charmaz K (2006) Constructing grounded theory: A practical guide through qualitative analysis. Sage.

21. Charmaz K (2014) Constructing grounded theory. Sage.

22. Bryman A (2016) Social research methods. Oxford university press.

23. Charmaz K (2000) Grounded theory: objectivist and constructivist methods. In Norman KD, Yvonne SL, editors. Handbook of Qualitative Research. Thousand Oaks: Sage Publication.

24. Government of Manitoba (2017) Review of Child Welfare Legislation in Manitoba Available from https://www.gov.mb.ca/fs/child_welfare_reform/pubs/discussion_ guide.pdf

25. Barrera J (2017) Indigenous child welfare rates creating 'humanitarian crisis' in Canada, says federal minister. Available from: https://www.cbc.ca/news/indigenous/ crisis-philpott-child-welfare-1.4385136

Copyright: (C2018 Cidro J. This is an open-access article distributed under the terms of the Creative Commons Attribution License, which permits unrestricted use, distribution, and reproduction in any medium, provided the original author and source are credited. 